\title{
NUMERICAL INVESTIGATION OF DETONATION PROPAGATION THROUGH SMALL ORIFICE HOLES
}

\author{
Ashish Vashishtha ${ }^{1^{*}}$ (D) 0000-0002-8385-3740 \\ Dean Callaghan $^{2}$ (iD 0000-0002-8435-6252 \\ Cathal Nolan $^{1}$ (D) 0000-0003-4748-3292 \\ Ralf Deiterding $^{3}$ (D) 0000-0003-4776-8183 \\ ${ }^{1}$ Department of Aerospace Mechanical and Electronics Engineering, Institute of Technology Carlow, \\ Kilkenny Rd, Moanacurragh, Ireland \\ 2 The Centre for Research and Enterprise in Engineering (engCORE), Institute of Technology Carlow, \\ Kilkenny Rd, Moanacurragh, Ireland \\ ${ }^{3}$ School of Engineering, University of Southampton, University Road, SO17 1BJ Southampton, UK \\ *ashish.vashishtha@itcarlow.ie
}

\begin{abstract}
Seeking to better understand the physical phenomena underlying detonation wave propagation through small holes (especially the phenomenon of detonation re-initiation or its failure), we investigated the propagation of a detonation wave along a tube filled with a hydrogen-oxygen mixture diluted with argon, in the presence of obstacles with a small orifice hole. Numerical simulations were performed in a two-dimensional domain using adaptive mesh refinement and by solving compressible Euler equations for multiple thermally perfect species with a reactive source term. A premixed mixture of $\mathrm{H}_{2}: \mathrm{O}_{2}: \mathrm{Ar}$ at a ratio $2: 1: 7$ at $10.0 \mathrm{kPa}$ and $298 \mathrm{~K}$ was used in a $90 \mathrm{~mm}$ diameter tube with a detonation wave travelling from one end. We found that a single orifice placed at $200 \mathrm{~mm}$ from one end of the tube, with varying diameters of $6,10,14,16,18,30$, and $50 \mathrm{~mm}$, showed an initial decoupling of the detonation wave into a shockwave and flame front. The detonation wave fails to propagate along the tube for orifice diameters less than $\lambda$, while it propagates by different re-initiation pathways for orifice diameters greater than $\lambda$, where $\lambda$ is the cell-width for regular detonation propagation.
\end{abstract}

Keywords: Detonation, propagation, hydrogen-oxygen mixture, numerical simulations, Adaptive Grid Refinement

Type of the work: Research Article

\section{INTRODUCTION}

Hydrogen fuel has recently received much attention, as a source of clean energy as well as an energy carrier in the development of renewable power-to-gas systems. Prior to the adoption of carbon neutral energy resources in the future, it may be required to use blended fuel, such as low carbon impact hydrogen or carbon neutral bio-methane for current natural gas-powered industrial plants, or even gas-network grids during the transition phase. Blending of various fuels can help to achieve stringent regulation targets on carbon emissions and reduce the overall impact of climate change. Using blends of hydrogen seems to be one of the cost effective and suitable methods for existing industrial plants [1] during the transition 
phase, without entailing significant infrastructural changes. With the development of various green hydrogen generation technologies as well as increased hydrogen usage after the transition phase [2], the use of hydrogen may become more cost-effective.

However, certain properties of hydrogen, such as its high diffusivity, low ignition energy, the possibility of its shock induced ignition and the embrittlement of some metals while transporting it, raise some of the main concerns hampering the uptake of hydrogen in many applications. The blending of hydrogen in the gas network in various European countries has been regulated and limited to not more than $10 \%$ due to the availability of current gas infrastructure [3]. On one hand, many researchers are working on developing systems and techniques for safe usage of hydrogen and hydrogen blends. On the other, research into advanced combustion concepts [4] is underway, seeking to boost the efficiency of existing combustion systems.

Among the promising concepts of this type is pressure gain combustion, which is fundamentally a constant volume process causing a flame to propagate at supersonic speed and have higher pressure increase across it. This self-sustainable combustion regime is called detonation combustion, and the travelling coupled flame along with shockwave is called the detonation wave $[4,5]$. When a premixed gaseous fuel-air mixture is ignited, a laminar flame initially propagates at very low speed and depending on the confined volume and further addition of turbulence, the flame can accelerate to higher speeds as a deflagration flame (at subsonic speeds). This deflagration wave may transition to a detonation wave after travelling at larger distances or due to the effect of a detonation enhancer device. This phenomenon of flame transition is called deflagration to detonation transition (DDT). Many researchers [6] have studied the DDT phenomenon in various long tubes for different fuel mixtures $[7,8]$ to characterize the DDT transition lengths. Blockages in the form of a Shchelkin spiral [9] or multiple orifice plates have traditionally been used as detonation enhancer devices. However, higher blockages and effective heat transfer may also cause failure in detonation propagation as well as flame quenching. Ciccarelli et al. [10] have studied detonation wave propagation through high blockage ratio orifice plates and found that passing a detonation wave through a high-blockage ratio obstacle may lead to an initial decoupling of the detonation wave into shock and flame. The decoupled shock and flame may fail to propagate as a detonation wave or re-initiate to detonation wave. Depending on the size of the blockage ratio, the reinitiation phenomenon may occur by different pathways, such as 1) immediate re-initiation, 2) re-initiation by shock reflection, 3) re-initiation by DDT, 4) re-initiation by hot spot or 5) re-initiation failure. It has been well-established in earlier studies [11] that the detonation wave may propagate in a self-sustaining manner from a tube to an unconfined space if the tube diameter $(d)$ is more than 13 times the detonation cell-width $(\lambda)$ for most of the fuel-air mixtures at a given pressure and temperature. In an unconfined space, the expansion fan formed at the corner of the tube may have the ability to penetrate through the central axis of the tube, with a diameter below the critical value of $13 \lambda$. However, in the case of larger tube diameters the new ignition may take place in the central axis zone before the expansion fan can penetrate, which can result in successful detonation propagation.

The propagation of a detonation wave through a small orifice plate in a confined tube will involve two major physical phenomena: decoupling of shock and flame through diffraction and reflection of shock from the tube wall before the orifice. The diffraction can cause suppression of transverse instability propagation and may cause detonation failure, while shock reflection can promote the ignition of shocked regions and generate new detonation cells. The interplay between these two phenomena, as well as DDT in some cases, can effectively govern the detonation propagation in single orifice laden tube. Peraldi et al. [12] have established the critical orifice diameter limit as $d \geq \lambda$ in order to propagate the detonation wave by DDT mechanism with some velocity deficit. However, for $d \geq 13 \lambda$, the detonation wave propagates with asymptotic C-J speeds. Zhang et al. [13] studied detonation wave propagation through a methane-air mixture and found that the pressure at which the detonation wave fails to propagate through the higher blockage ratio can be defined as the critical pressure. Moreover, the competing 
diffraction and shock reflection effects may cause detonation failure and re-initiation for larger blockage ratio orifice plates. It was suggested that a maximum blockage ratio of 0.962 may cause detonation wave propagation through re-initiation for a minimum $d / \lambda>1$. Sun et al. [14] studied detonation wave propagation through orifice holes from $10 \mathrm{~mm}$ to $60 \mathrm{~mm}$ in diameter inside a $90 \mathrm{~mm}$ tube for lean to rich equivalence ratios of $\mathrm{H}_{2}$ - air mixture. They found that detonation wave propagation through small orifice holes is possible if the diameter of the orifice hole is more than the characteristic cell size.

The study of detonation wave propagation through small openings is important not only for developing a database for the design of safety devices such as detonation arrestors in the chemical industry, but also for the fundamental understanding of detonation wave propagation modes. Furthermore, the understanding and correlation for re-initiation run-up lengths may also assist the design and development of pressure gain combustion systems. The overall motivation of the current study is to understand the underlying physical phenomena and their effects on detonation propagation through small holes for various fuels and their blends. It is envisioned that a database for modes of detonation wave propagation through different small orifice holes using numerical simulations will be developed so that a range of applied studies can be carried out - for example, the design and development of detonation arrestors for various fuel blends, the study of optimised limit of hydrogen blends in the gas grid network or re-initiation in pressure gain combustion systems. In this initial study, an orifice plate with a range of blockage ratios in a confined tube was investigated in a two-dimensional domain. An open-source program, Adaptive Mesh Refinement Object-oriented C++ (AMROC) $[15,16]$ based on the Structured Adaptive Mesh Refinement (SAMR) approach was used with a detailed reaction model. AMROC was chosen because it has been validated for various regular detonation propagation simulations [15, 16, 17, $18,19,20,21]$. The operating conditions were selected based on an earlier AMROC validated case of detonation wave propagation through bend pipes $[16,19]$.

The primary objectives of the current study were: 1) to model and investigate the detonation wave propagation modes through the small orifice holes for a hydrogen-oxygen mixture with diluted argon, 2) to contribute to a better understanding of the various detonation propagation modes through small orifice holes and devise a method for quantifying the critical orifice size with minimal computational resources.

\section{NUMERICAL METHOD}

Two-dimensional numerical simulations were performed by solving compressible reactive multispecies Euler equations with detailed chemical kinetics $[15,16,22]$ as follows:

$$
\frac{\partial \boldsymbol{U}}{\partial t}+\frac{\partial \boldsymbol{F}}{\partial x}+\frac{\partial \boldsymbol{G}}{\partial y}=\boldsymbol{S}
$$

where,

$$
\boldsymbol{U}=\left\{\begin{array}{c}
\rho_{1} \\
\cdot \\
: \\
\rho_{n} \\
\rho u \\
\rho v \\
e
\end{array}\right\}, \quad \boldsymbol{F}=\left\{\begin{array}{c}
\rho_{1} \\
\cdot \\
: \\
\rho_{n} u \\
\rho u^{2}+p \\
\rho u v \\
(e+p) u
\end{array}\right\}, \quad \boldsymbol{G}=\left\{\begin{array}{c}
\rho_{1} v \\
\cdot \\
: \\
\rho_{n} v \\
\rho u v \\
\rho v^{2}+p \\
(e+p) v
\end{array}\right\} \text {, and } \quad \boldsymbol{S}=\left\{\begin{array}{c}
\omega_{1} \\
\cdot \\
: \\
\omega_{n} \\
0 \\
0 \\
0
\end{array}\right\}
$$


Total Density:

$\rho=\sum_{i=1}^{n} \rho_{i}$

Energy:

$e=\rho h-p+\frac{1}{2} \rho\left(u^{2}+v^{2}\right)$

Specific Enthalpy:

$h=\sum_{i=1}^{n} \frac{\rho_{i} h_{i}}{\rho}$

Equation of State:

$p=\sum_{i=1}^{n} \rho_{i} \frac{R}{w_{i}} T$

where $\omega_{1}$ is the specific mass production rate of each species dependent on the chemical reaction mechanism model, $w_{i}$ is the molecular weight of each species, $R$ is the universal gas constant and $T$ is the local temperature. The hydrogen-oxygen combustion (in the presence of Argon) is modelled by 9 species and 34 elementary reactions in a chemical kinetic mechanism, which was derived from Westbrook's detailed mechanism [23] of hydrocarbon gaseous detonation. AMROC uses a time-operator splitting approach or method of fractional steps to decouple hydrodynamic transport and chemical reactions numerically [15]. In the current solver [16], Godunov splitting is adopted for decoupling and the second-order accurate MUSCL-TVD finite volume method (FVM) for the convective flux discretization. A hybrid Roe-HLL Riemann solver is used for the construction of the inter-cell numerical upwind fluxes, while the Van-Albada limiter is applied with the MUSCL reconstruction to construct a second-order method in space. The second-order accurate MUSCL-Hancock technique is adopted for time integration. The dynamic time stepping is used for all simulations by keeping the CFL number at 0.95. The structured automatic mesh refinement (SAMR) method based on various flow parameters was utilized here, which may have low numerical diffusion in highly refined regions, as well as no physical diffusion. Mahmoudi et al. [18] compared the Euler, Navier-Strokes (NS) and LES simulations for simulating detonation and found that the modelling of physical diffusion is important for accurately modelling the dissipation of small-scale flow-features and irregular detonations. However, the overall flow structure does not differ significantly between Euler and NS in highly refined grids for regular detonation fronts. A highly diluted hydrogen-oxygen mixture with argon in low pressure experimentally exhibits regular detonation propagation [24]. Hence, using Euler solutions to understand the detonation propagation mechanism in various orifice holes can provide adequate qualitative accuracy for a comparative study. The details of the computation domain, boundary and initial conditions, solution procedure as well as the grid independency test will be discussed in the following subsections.

\subsection{Computational Domain}

The overall initial computational domain consists of a two-dimensional $1000 \times 90 \mathrm{~mm}$. rectangle. The schematic of the computational domain with initial and boundary conditions as well as the location of the orifice plate is shown in Fig. 1. It consists of a $1000 \mathrm{~mm}$ long tube with an orifice plate, which is located $200 \mathrm{~mm}$ from left wall, used as the obstacle. The orifice plate has a thickness of $10 \mathrm{~mm}$, while 
the orifice plate hole diameter varied between $d=6,10,14,16,18,30$ and $50 \mathrm{~mm}$. The tube was filled with an argon diluted hydrogen oxygen premixed mixture $\left(\mathrm{H}_{2}: \mathrm{O}_{2}: \mathrm{Ar}\right)$ with a ratio of 2:1:7 at a pressure of $10 \mathrm{kPa}$ and a temperature of $298 \mathrm{~K}$. Slip and adiabatic boundary conditions are assumed at the wall and the tube outlet was considered a supersonic outlet boundary. A regular oscillating detonation wave propagation with a Chapman-Jouguet speed [5] was imposed up to an axial distance of $10 \mathrm{~mm}$ from the left end of the tube at time, $\mathrm{t}=0$.

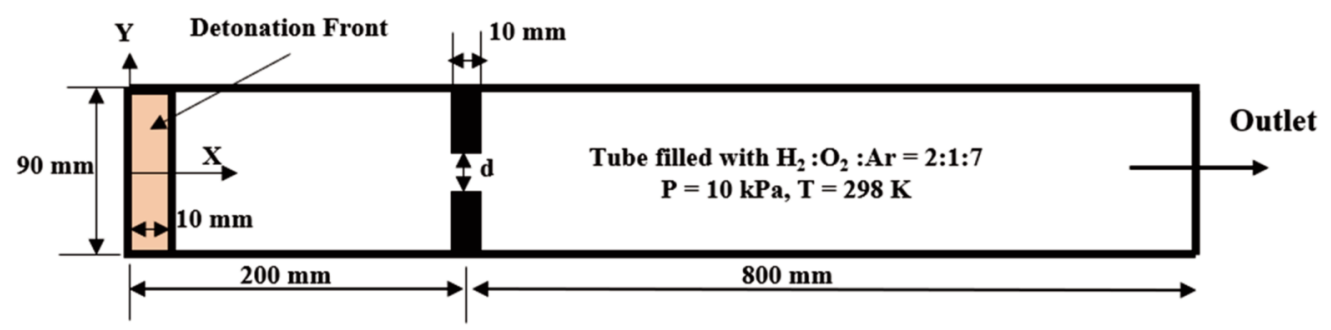

Fig. 1. Computational Domain and Boundary Conditions.

\subsection{Solution Procedure}

The first step for initializing the solution was to impose a regular oscillating detonation front at the entry of the tube. To generate a two-dimensional detonation front, initially a 1D ZND solution was obtained for operating conditions and the fuel-oxidiser mixture. Following this, the 1D ZND solution was used to initialise the regular detonation front in a two-dimensional straight tube by perturbing it with a small unreacted pocket in a different simulation. The 1D ZND theory for detonation structure modelling in $\mathrm{H}_{2}: \mathrm{O}_{2}$ :Ar mixture in a ratio of $2: 1: 7$ at $10 \mathrm{kPa}$ and $298 \mathrm{~K}$ [18] computed the detonation velocity to be $1638.5 \mathrm{~m} / \mathrm{s}$, the von -Neuman pressure rise to be $269.5 \mathrm{kPa}$ and the induction time, $t_{i g}=2.21 \mu \mathrm{s}$ and length is $l_{i g}=0.878 \mathrm{~mm}$. The two-dimensional perturbed simulation resulted in regular oscillating detonation cells with a width of $16 \mathrm{~mm}$. A snapshot of a single cell of regular detonation cells was periodically imposed up to an initial $10 \mathrm{~mm}$ axial length in the computational domain as shown in Fig. 1. All simulations were performed for a total time of $800 \mu \mathrm{s}$. After the $2 \mathrm{D}$ detonation front cellular structure was imposed, it reaches near the orifice obstacle at $108 \mu \mathrm{s}$. Figure 2 shows the contour plots of the temperature, pressure and $\mathrm{OH}$ mass fraction plots for the developed detonation front before the orifice.

(a)

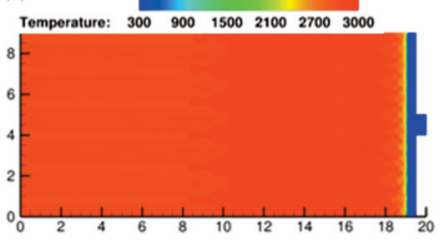

(b)

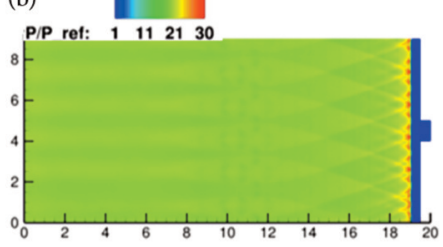

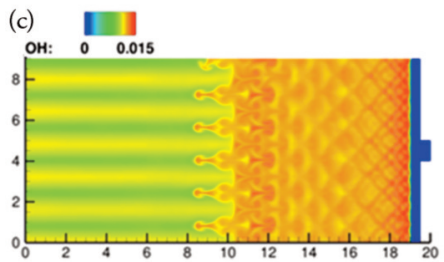

Fig. 2. Contours of the detonation front before the orifice hole: (a) Temperature (b) Pressure Ratio and (c) $\mathrm{OH}$ Mass Fraction.

\subsection{Grid Independence Study}

Deiterding et al. [19] concluded that a very high-resolution grid may be required, up to 44 to 67 points $/ l_{i g}$, to resolve up to the secondary triple point. However, using such a high-resolution grid in the current domain may lead to 2-3 weeks of computational time for a single case, depending on 
computational resources. The main objective of the current study is not to resolve all scales of the simulation, but to understand the propagation of a detonation front through small orifice holes. Hence, it was attempted in this study to use minimal computational resources to achieve a fast solution for the detonation propagation. The initial grid size is considered as $1 \times 1 \mathrm{~mm}$ and a further three levels of refinement are selected with minimum a grid size of $0.25 \mathrm{~mm}$, which results in 3.51 points $/ l_{i g}$. This resolution may not capture the intermediate species very accurately but can provide an adequate qualitative comparison of the detonation propagation mechanism. Further high-resolution results will be obtained in future work to develop further validation and understanding over a wide operating range. In order to select three level of refinements $(2,2,2)$ a grid independence study was performed for 2 level ( $\min 0.5 \mathrm{~mm}), 3$ level $(\min 0.25 \mathrm{~mm})$ and 4 level $(\operatorname{min~} 0.125 \mathrm{~mm})$ of refinements based on the thresholds of various parameters. These values for density, temperature and pressure were $\varepsilon_{\rho}=0.05, \varepsilon_{T}=500$, $\varepsilon_{P}=4000$ respectively. Furthermore, the thresholds for mass fractions of various main and intermediate species were $\varepsilon_{\mathrm{O}_{2}}=\varepsilon_{\mathrm{H}_{2}}=0.0004, \varepsilon_{\mathrm{H}_{2} \mathrm{O}}=0.0002, \varepsilon_{H}=0.001, \varepsilon_{O}=0.001, \varepsilon_{O H}=0.001$, where $\varepsilon$ is the gradient of mentioned quantities.

(a)

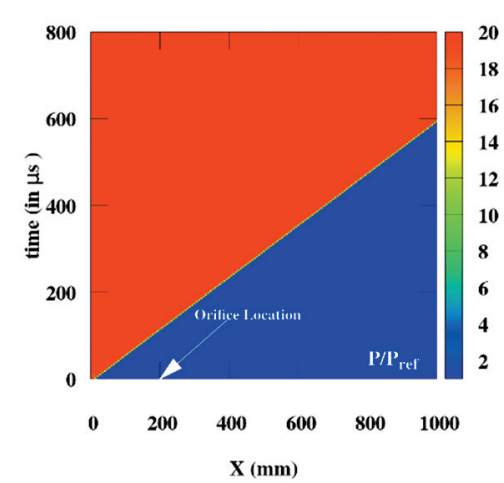

(b) x-t Diagram No Blockage Level 4

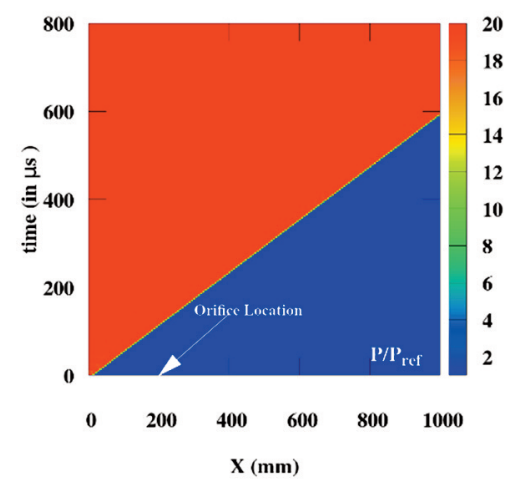

(c) Centerline Pressure Tube with no Orifice

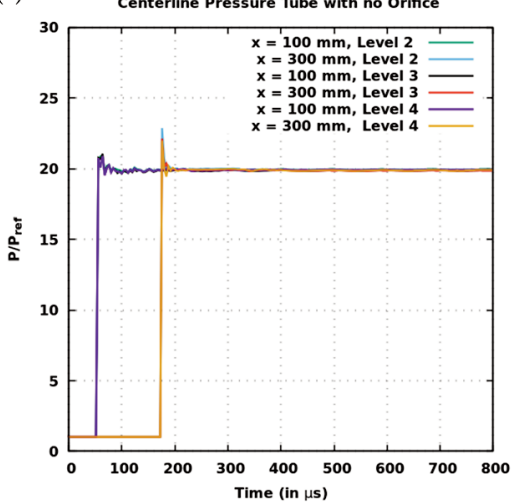

Fig. 3. Straight Tube: $x^{-t}$ diagram for (a) Level 3 and (b) Level 4 and (c) pressure rise at $\mathrm{x}=100 \mathrm{~mm}$ and $300 \mathrm{~mm}$ locations for level 2, 3 and 4 automatic grid refinements.

Figures 3(a) and 3(b) show the $x^{-t}$ diagram of the non-dimensional pressure ratio for a straight tube without an obstacle using refinement levels 3 and 4 . The detonation wave propagated in this tube at constant CJ speed and reaches at the other end at $t=610 \mu \mathrm{s}$ for both refinement levels. Figure 3(c) shows 
the pressure rise at two different locations for each tube with respect to refinement levels 2, 3, and 4 . The regular detonation front propagation does not vary significantly for the coarse grid refinements. However, the various contour plots at different level grid refinement show small scale flow feature variations. The small-scale flow feature may not affect the detonation wave propagation for small distances, until the decoupled detonation reinitiates or completely fails. Hence, the level 3 grid was selected for all simulations in this study.

\section{RESULTS AND DISCUSSION}

Simulations were performed for seven different orifice hole diameters ranging from $6 \mathrm{~mm}$ to $50 \mathrm{~mm}$, corresponding to $0.375 \lambda$ and $3.125 \lambda$, respectively. The centre of the orifice hole in each case coincides with the centreline axis of the tube. All the simulations were performed for $800 \mu \mathrm{s}$ and solutions were saved at each time-step of $4 \mu \mathrm{s}$. As the range of orifice diameters was well below the $13 \lambda$ limit, decoupling of the flame and shock was observed for all cases. The propagation or failure of the detonation front was observed and analysed by extracting the flame and shock tip location after passing through the orifice along the axis of the tube.

The results and discussion are organised as follows: the first subsection discusses all the simulation results by extracting shock and flame tip location and speeds in the axial direction. Following this, $x^{-t}$ (space-time), plots have been created and are discussed for select orifice diameters along with the temperature contour plots to visualize the flow-structures during the detonation failure and reinitiation cases.

\subsection{Flame and Shock Propagation in the Axial Direction}

Figures 4(a) and 4(b) show the shock tip and flame tip locations in axial direction with respect to time for various orifice hole diameters. Figures 5(a) and 5(b) show non-dimensional speeds of the shock tip and the flame tip along the tube plotted with time. The non-dimensional speeds were computed by taking the ratio with the Chapman-Jougeut speed for the operating mixture. Analysis of shock-flame locations and speed can provide preliminary details of shock flame or detonation wave propagation.

(a)

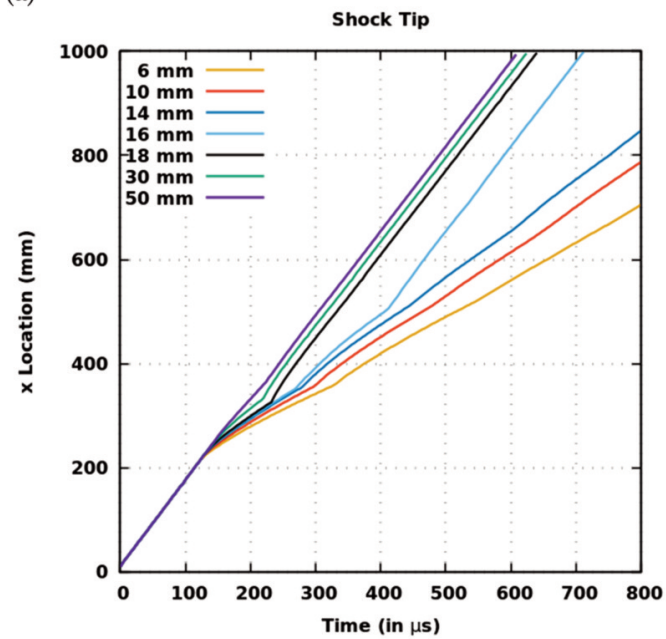

(b)

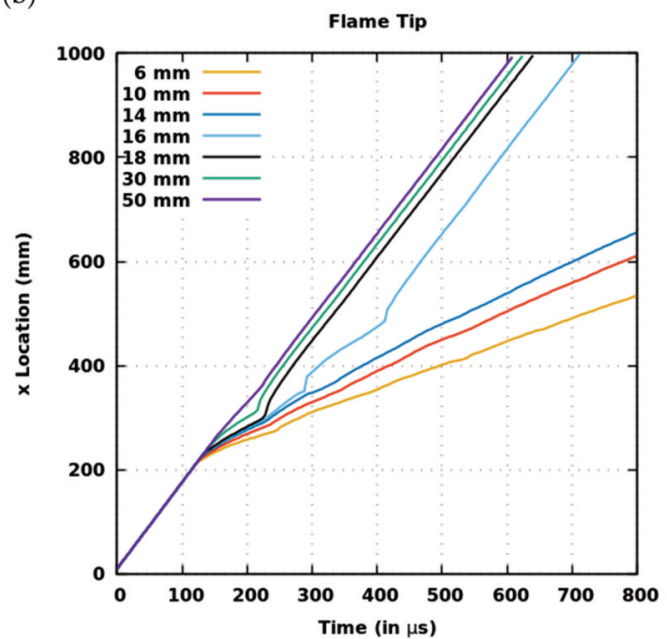

Fig. 4. Location of (a) Shock Tip and (b) Flame Tip along the tube axis with orifice holes of different sizes. 
Figures 4(a) and 4(b) effectively plot $\mathrm{x}$ vs. $\mathrm{t}$, the higher slope at any $\mathrm{x}$-location or time represents higher velocity. The shock and flame do not reach the right side of tube within $800 \mu s$ for orifice hole diameters $6 \mathrm{~mm}, 10 \mathrm{~mm}$ and $14 \mathrm{~mm}$; however, both shock and flame cross the $1000 \mathrm{~mm}$ location in the tube before the end of the computing time for orifice diameters $16 \mathrm{~mm}, 18 \mathrm{~mm}, 30 \mathrm{~mm}$ and $50 \mathrm{~mm}$. The shock-flame reaches the right end of the tube in the shortest time for the $50 \mathrm{~mm}$ orifice hole at approximately $610 \mu \mathrm{s}$, similar to the no orifice case. For an orifice plate located at $200 \mathrm{~mm}$ all the plots start deviating near this location at the same time (indicating that the detonation front travels without a velocity deficit before the obstacle). However, there is a slight deviation for all the cases, with the $50 \mathrm{~mm}$ orifice hole showing the lowest deviation. It is suggested that the decoupling of the flame and shock occurs for all the cases, but for the $50 \mathrm{~mm}$ orifice hole, it may be momentarily. The slope for shock and flame location plots for the $50 \mathrm{~mm}$ orifice hole are almost identical, indicating that after momentarily decoupling, the shock and flame couple together immediately and propagate as a detonation front. For the lower orifice diameters of $30 \mathrm{~mm}, 18 \mathrm{~mm}$, the decoupling time slightly increases, but after some distance the shock and flame couple with each other and propagate together. In Fig. 4(a) and 4(b), the $16 \mathrm{~mm}$ diameter case shows slight deviation in shock and flame locations after crossing the orifice, but after approximately $420 \mu \mathrm{s}$, the shock and flame propagate together and reach the right end of the tube after approximately $710 \mu \mathrm{s}$. The slope in Fig. 4(a) for the shock location is higher than the corresponding flame location in Fig. 4(b) for orifice hole diameters less than $16 \mathrm{~mm}(d<\lambda)$. This would indicate that after decoupling of the initial shock and flame, they remain decoupled and travel different distances at the same time, with the shock travelling a longer distance than the flame. This suggests that the detonation front failed in propagating through orifice diameters less than $16 \mathrm{~mm}$ $(d<\lambda)$.

(a)

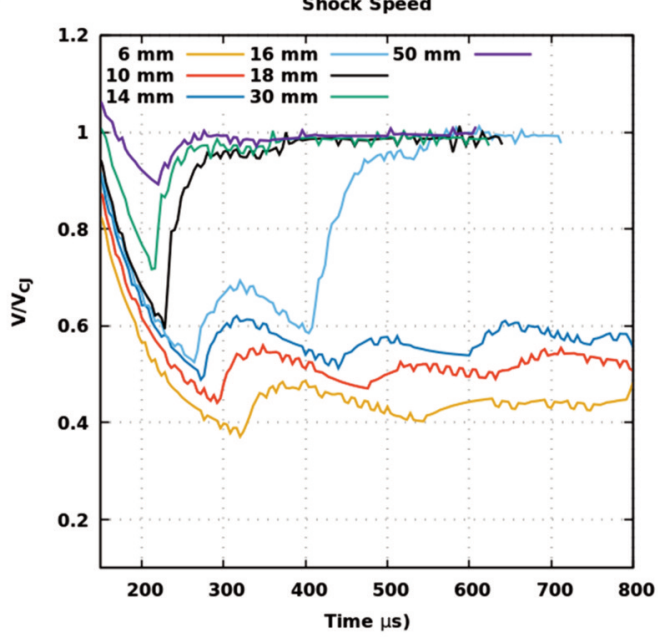

(b)

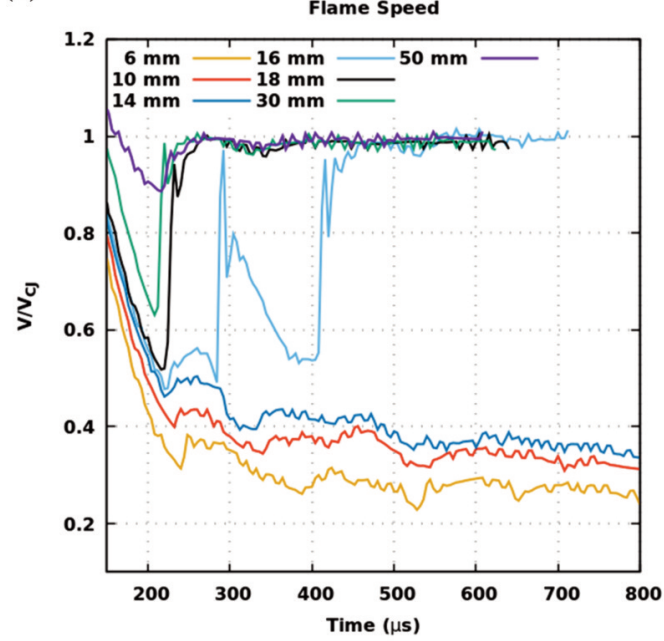

Fig. 5. Speed of (a) Shock Tip and (b) Flame Tip along the tube axis with orifice holes of different sizes.

Figures 5(a) and 5(b) show the non-dimensional velocity variation computed from the shock and the flame front locations plot by calculating the derivatives and plotting with time. The shock and flame speed curves show similar trends, such as reducing the propagation speed initially after passing through orifice hole and after reaching a local minimum it further increases. However, before reaching the first minima, the shock propagation speed decreases less than the flame propagation speed for the $18 \mathrm{~mm}$, $30 \mathrm{~mm}$, and $50 \mathrm{~mm}$ orifice diameter cases. This indicates the decoupling of the shock and flame after 
passing through the orifice holes. In the $18 \mathrm{~mm}, 30 \mathrm{~mm}$, and $50 \mathrm{~mm}$ orifice diameter cases, the shock and flame speeds suddenly increase and approach $\mathrm{V} / \mathrm{V}_{\mathrm{CJ}}=1$, indicating the re-initiation and re-coupling of shock and flame quickly and propagation as a detonation front. The decoupling duration increases with a decrease in orifice diameter. In the case of the $6 \mathrm{~mm}, 10 \mathrm{~mm}$, and $14 \mathrm{~mm}$ orifice diameters (cases with $d<\lambda$ ), the shock and flame decouple after passing through the orifice and the shock and flame speeds decrease. After the first decrease there is slight increase in shock and flame speeds, but both shock and flame are not able to meet and further propagates at different speeds. For the $16 \mathrm{~mm}$ orifice diameter $(d=\lambda)$ case, it is found that after the initial decoupling of shock and flame, having passed through the orifice, the flame tries to propagate at a higher speed than the shock which may be due to the sudden flame ignition away from the centreline, but fails to couple with shock and attain another local minimum. At the next speed increase, the shock and flame couple together and propagate as a detonation front. One interesting observation here is that there is a sudden increase in flame speed but the increase in shock speed is gradual before re-initiation. This may indicate that the passing of a shock may have highly compressed the unburnt fuel pocket which has suddenly self-ignited and propagated further as a detonation front. The time-series in Fig. 5(a) and 5(b) shows shorter curve for orifice hole diameter $16 \mathrm{~mm}$ and higher because the re-initiated detonation front exited from the outlet end of $1 \mathrm{~m}$ computation domain before the total computation time of $800 \mu \mathrm{s}$.

These above results show that as the orifice diameter increases from the $6 \mathrm{~mm}$ to $14 \mathrm{~mm}$, the detonation wave fails to re-initiate in propagating as a detonation wave after decoupling through the orifice hole. The $16 \mathrm{~mm}$ orifice diameter behaves as a limiting case, where the decoupled shock and flame re-initiate after a certain time or distance and then propagate as a detonation front further along the tube. The orifice diameters greater than the detonation cell width $(18 \mathrm{~mm}, 30 \mathrm{~mm}$, and $50 \mathrm{~mm})$ initially exhibit decoupling of shock and flame, but re-initiate quickly after passing a short distance through the orifice. There are two phenomena that, as mentioned in previous studies $[4,5,6,7,8]$, are responsible for different pathways of re-initiation or failure: 1) diffraction of the detonation wave, and 2) shock reflection. The local diffraction of the detonation wave is caused by the expansion fan formation at the corner. The smaller concentric orifice holes have a diffraction corner closer to the central axis. Hence, the decoupling of flame and shock can be quicker and stronger. Further, bigger orifice holes have a diffraction corner closer to the tube wall. The decoupled shock may reflect from the tube wall and highly compress the decoupled unburnt region of shock and flame, which may lead to detonation wave formation by initiating the flame behind the shock propagating in the axial direction. To better understand these effects, further $x$ - $t$ plots of pressure and temperature along the central axis are presented in the following sections as well as temperature contours for the three selected cases: $10 \mathrm{~mm}, 16 \mathrm{~mm}$, and $18 \mathrm{~mm}$. The other orifice diameter cases behave in a similar manner, hence have not been discussed here.

\subsection{Immediate re-initiation through Shock Reflections $(d>\lambda)$}

This subsection deals with the two-dimensional simulation results obtained for detonation propagation through an $18 \mathrm{~mm}$ orifice diameter $(d>\lambda)$. Figures $6(\mathrm{a})$ and $6(\mathrm{~b})$ show the propagation of a detonation wave though an $18 \mathrm{~mm}$ orifice by plotting the centreline $\mathrm{x}^{-\mathrm{t}}$ plot of non-dimensional temperature and pressure. The location of the orifice is highlighted at the $200 \mathrm{~mm}$ location. The temperature contour will provide information on flame propagation and the pressure contour plot will provide information about the shock propagation and re-initiation point, where there is a sudden change in pressure through pressure gain combustion. It has been already observed that the detonation propagation through an orifice diameter greater than $18 \mathrm{~mm}$ occurs by a similar method, however the decoupling duration is shorter when compared to the $18 \mathrm{~mm}$ diameter case. The $\mathrm{x}$-t plots also provide information about the wave propagation throughout the tube during the total time of the simulation. 
(a) x-t Diagram Orifice $18 \mathrm{~mm}$

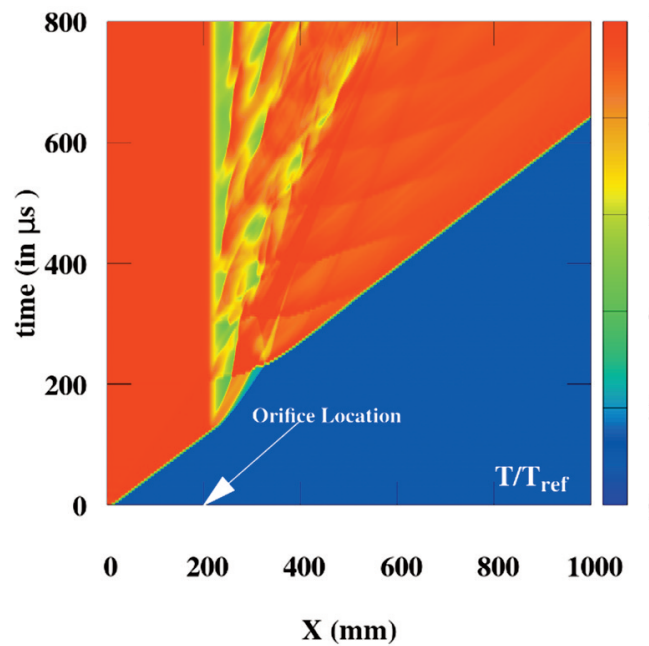

(b) x-t Diagram Orifice $18 \mathrm{~mm}$
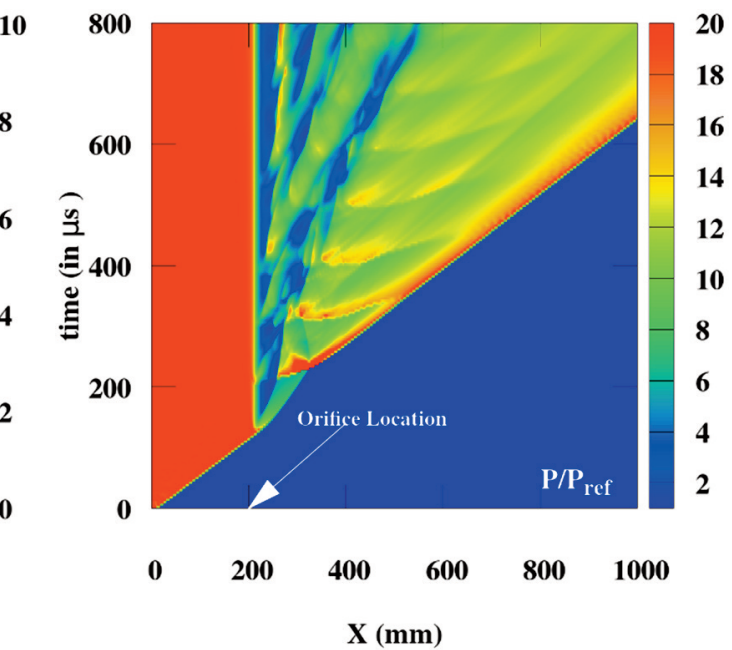

Fig. 6. $\mathrm{x}$-t diagram of (a) temperature ratio (b) pressure ratio for detonation wave propagation through an $18 \mathrm{~mm}$ orifice hole.

The temperature contours in Fig. 6(a) show reduced flame speed near the orifice and separation of shock and flame causing the shock to move ahead with a slight elevation in temperature of an unreacted zone behind the shock. In Fig. 6(b), the pressure contours also show the reduction in shock speed, however the slope of the pressure curve (shock) is lower than the slope of the high temperature (flame) curve, indicating that the shock travels at a higher speed than the flame. After a distance of approximately $310 \mathrm{~mm}$, the re-initiation of detonation occurs, which can be deduced by a sudden increase in pressure near the $310 \mathrm{~mm}$ location, similarly to the sudden increase in temperature at the same location. The local re-initiation detonation at this location travels in both the forward and backward directions. The complex wave interaction behind the detonation wave is clearly visible in the temperature and pressure $\mathrm{x}^{-\mathrm{t}}$ plots. There are multiple local ignitions visible near the centreline in these $\mathrm{x}^{-\mathrm{t}} \mathrm{t}$ plots, which is necessary for propagation of the detonation front in the whole tube. While $x^{-t}$ plots can provide great information about the wave propagation, it may nevertheless be difficult to clearly recognize the mechanism of re-initiation through only $x^{-} t$ plots. To understand the re-initiation phenomena in the studied case, temperature contours at different time steps have been plotted in Figure 7 . The time $\mathrm{t}=0$ is the start of the simulation, when the modelled detonation front is imposed at the $\mathrm{x}=10 \mathrm{~mm}$ location. In all the studied cases, the detonation front reaches close to the orifice location at $\mathrm{t}=108 \mu s$. As the orifice diameter is $18 \mathrm{~mm}(d<13 \lambda)$, the detonation front does decouple into shock and flame. At time $\mathrm{t}=148 \mu \mathrm{s}$, the region between the decoupled shock and flame can be inferred as a slightly elevated temperature region. The expansion fan at the corner does cause an increase in speed of flow near the centreline after exiting from the orifice and may lead to a reduction in pressure locally; hence in a constant volume region there may be a decrease in local temperature.

The spherical shock wave (or circular blast wave in 2D) travels in all directions. Additionally, at $\mathrm{t}=200 \mu \mathrm{s}$ the gap between the shock front and flame front increases and the shock may reflect from the upper and lower walls (or cylindrical walls in 3D). The reflected shock can quickly compress the unreacted region between flame and shockwave (before the unreacted region travels a far distance) and it will auto-ignite and generate two triple points travelling in the transverse direction. This re-initiation due to shock reflection will further propagate in the axial direction as the detonation front, 
as seen at $\mathrm{t}=300 \mu \mathrm{s}$ and $\mathrm{t}=400 \mu \mathrm{s}$. The current study only considers the decoupling and coupling of flame and shock up to the re-initiation point. A further understanding of the propagation of the reinitiated detonation front and cellular structure quantification is not within the scope of this current study but will be considered in future work.

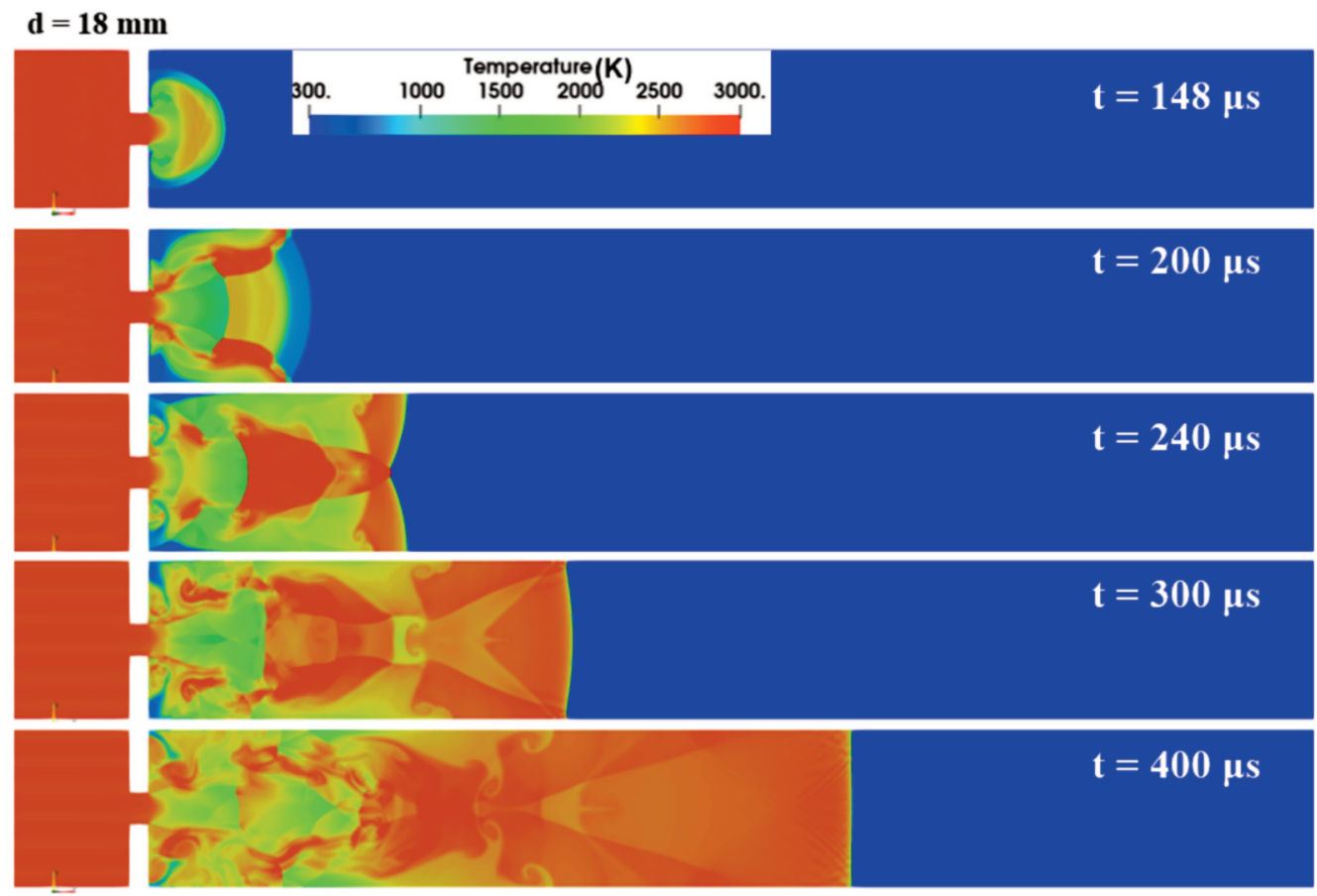

Fig. 7. Temperature contours for Detonation wave propagation through $18 \mathrm{~mm}$ orifice hole.

\subsection{Multiple re-initiation in the limiting case $(d=\lambda)$}

The simulation results for an orifice diameter equal to the cell width are presented in this section. As it was the limiting case, achieving a converged solution required a few trials of varying the Courant number. The results should be used for qualitative purposes only. Figures 8 (a) and 8(b) show the $x^{-t}$ plot for non-dimensional temperature and pressure contours along the centreline of the tube with a $16 \mathrm{~mm}$ diameter orifice plate. The $x^{-t}$ plots shown in Fig. 8(a) and 8(b) highlight immediate decoupling of flame and shock as the detonation wave passes through the orifice hole. The shock travels at a faster speed than the flame. It was interesting to observe that there were multiple attempts of re-initiation occurring along the centreline. The first occurred at approximately $\mathrm{x}=370 \mathrm{~mm}$ and the second at $\mathrm{x}=500 \mathrm{~mm}$. The first attempt of re-initiation failed, and the second attempt of the re-initiation was successful. The flame and shock propagate as a detonation front after the second re-initiation. There is also complex wave interaction, which can be observed by both the $x^{-} t$ plots. To further understand the re-initiation process in this case, Fig. 9 shows the temperature plots at different time stamps as the detonation wave decouples into slower flame and faster shock. The spherical shock (circular in 2D) propagates in a similar manner to the $\mathrm{d}=18 \mathrm{~mm}$ case at $\mathrm{t}=148 \mu \mathrm{s}$. 
(a)

x-t Diagram Orifice $16 \mathrm{~mm}$

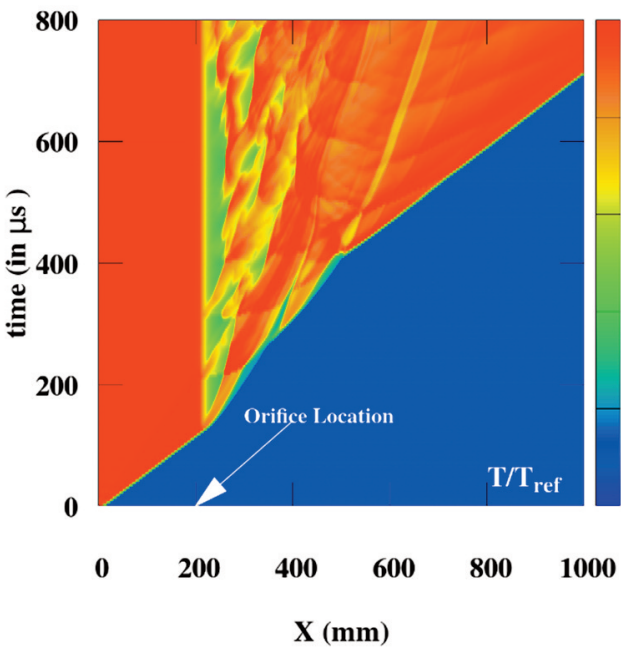

(b)

x-t Diagram Orifice $16 \mathrm{~mm}$

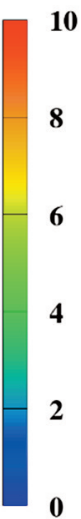

8
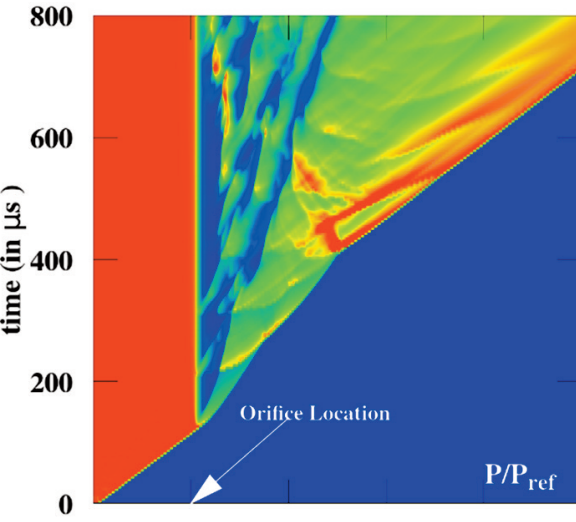

20

18

16

$0 \quad 200$

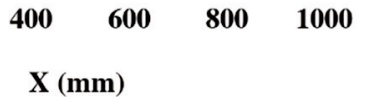

Fig. 8. $\mathrm{x}$-t diagram of (a) Temperature ratio (b) Pressure ratio for detonation wave propagation through a $16 \mathrm{~mm}$ orifice hole.

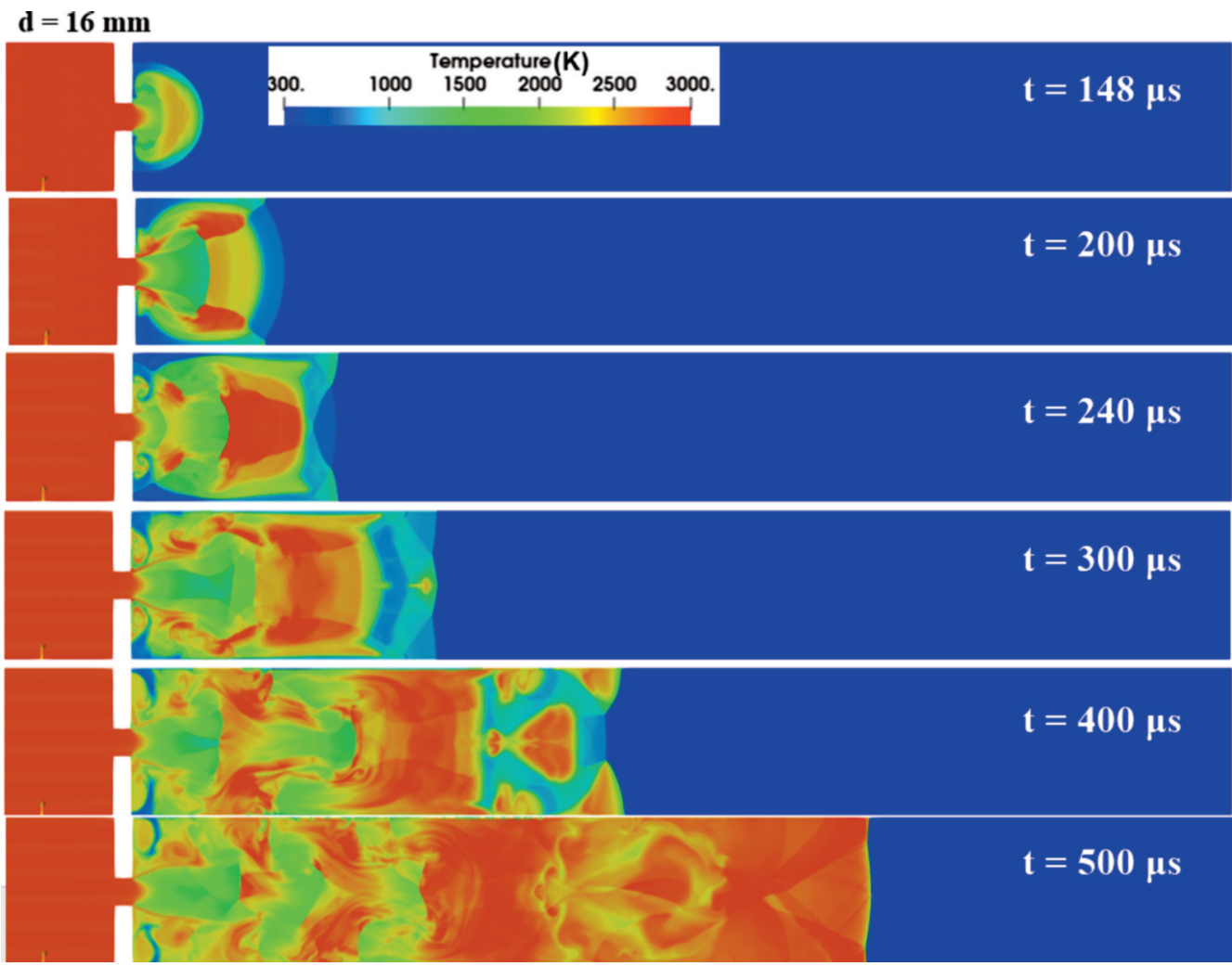

Fig. 9. Temperature contours for detonation wave propagation through a $16 \mathrm{~mm}$ orifice hole. 
At time $\mathrm{t}=200 \mu \mathrm{s}$, the gap between the shock and flame front increases and an almost similarly sized unreacted zone can be observed as in the $\mathrm{d}=18 \mathrm{~mm}$ case. At time $\mathrm{t}=240 \mu \mathrm{s}$, the difference between the flow features are more clearly visible than when compared to the $\mathrm{d}=18 \mathrm{~mm}$ case. The reflected shock can ignite some of the unreacted zone, but the shockwave has already progressed ahead of ignition zone, which leads to partial ignition of the unreacted zone. Two triple points can already be observed in the unreacted zone. At time $\mathrm{t}=300 \mu \mathrm{s}$, the unreacted zone has become larger and the merging of the triple point in the unreacted zone can ignite the unreacted zone near the shock front. This provides an opportunity for first re-initiation. However, the larger unreacted zone could not burn completely in the first re-initiation opportunity and fails to propagate as a detonation front. At time $\mathrm{t}=400 \mu \mathrm{s}$, multiple ignitions near the wall are observed, which may be caused by triple point movement in the unreacted zone. The multiple reacted zone pockets interact near the centreline and due to the merging of triple points a second opportunity for re-initiation becomes possible. Local explosions near the centreline after merging of triple points re-initiate the detonation front successfully, which propagates further as a detonation wave as can be seen at time $\mathrm{t}=500 \mu \mathrm{s}$.

\subsection{Re-initiation failure $(d<\lambda)$}

The simulation results for an orifice diameter of $10 \mathrm{~mm}$, which is less than detonation cell-width, are presented in this section. As reported in previous sections, the detonation re-initiation fails in the case of orifice diameters less than the cell width. Figure 10(a) and 10(b) show the $x^{-t}$ plots for non-dimensional temperature and pressure at the centreline of the tube, which confirms the same.

(a)

x-t Diagram Orifice $10 \mathrm{~mm}$

(b)

x-t Diagram Orifice 10 mm

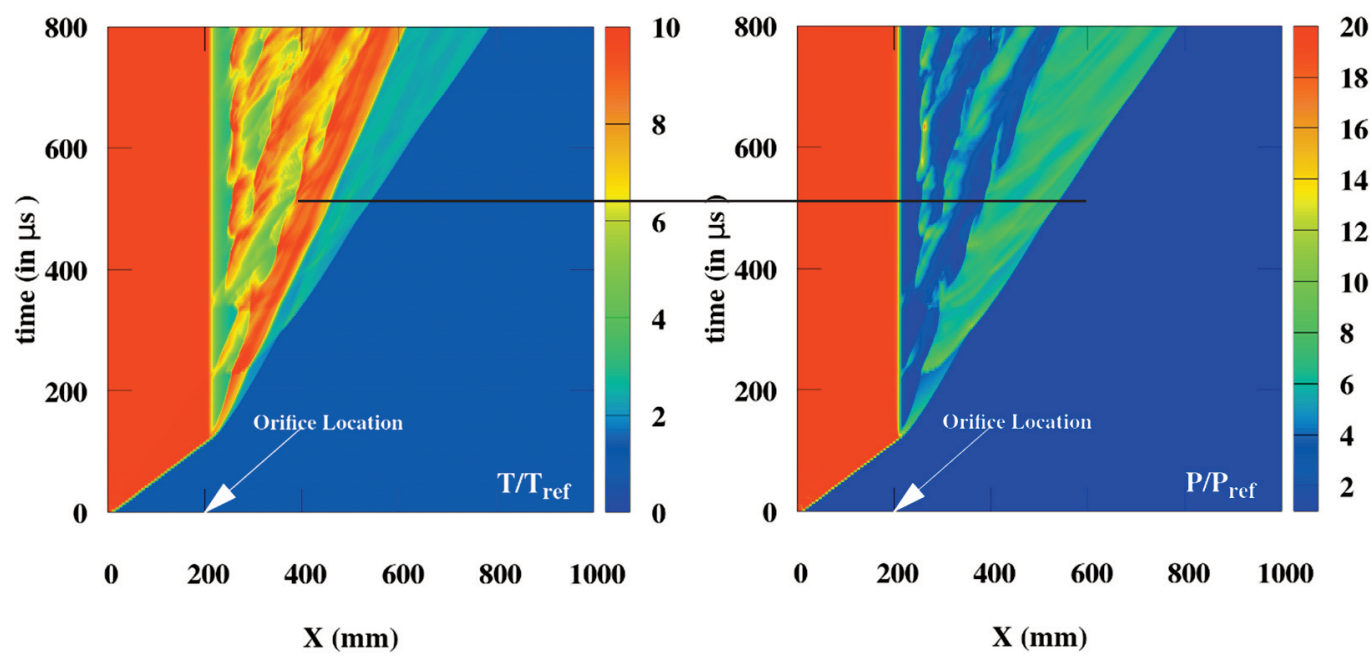

Fig. 10. $\mathrm{x}$-t diagram of (a) Temperature ratio (b) Pressure ratio for detonation wave propagation through a $10 \mathrm{~mm}$ orifice hole.

As the detonation front passes through the orifice, in Fig. 10(a) and 10(b), it decouples into flame and shockwave. In the $\mathrm{x}^{-} \mathrm{t}$ plot for temperature, the high temperature zone represents the flame and the slightly elevated temperature zone represents the unreacted zone behind the shockwave. It is clear only from the temperature contours that the shock front travels faster than the flame front in this case and the unreacted zone increases with time. The flame never catches up to the shock, or the shock / reflected 
shock never provides an ignition opportunity to re-initiate the detonation front. The pressure contour in the $\mathrm{x}^{-\mathrm{t}}$ plot shows the shock propagation and interaction of the reflected shocks at multiple locations but these reflected shock interactions are always behind the shock and may not provide sufficient energy to re-initiate the flame in the unreacted zone. The travelling deflagration flame slightly increases the pressure up to $80-100 \mathrm{kPa}$ but never catches up to the von-Neumann pressure rise $(270 \mathrm{kPa})$. Further temperature contours at different timestamps are shown in Fig. 11 which illustrate the interactions of various flow-features that may cause the failure in re-initiation. At time $\mathrm{t}=148 \mu \mathrm{s}$, the detonation front decouples into a flame and shockwave. The extent of the spherical region (circular in 2D) is shorter at the same time in comparison to $\mathrm{d}=16 \mathrm{~mm}$ and $18 \mathrm{~mm}$. At time $\mathrm{t}=200 \mu \mathrm{s}$, the spherical shock has already reflected from the side walls but the unreacted zone between front shock and flame in this case $(\mathrm{d}=10 \mathrm{~mm})$ is slightly larger than the previous two cases.

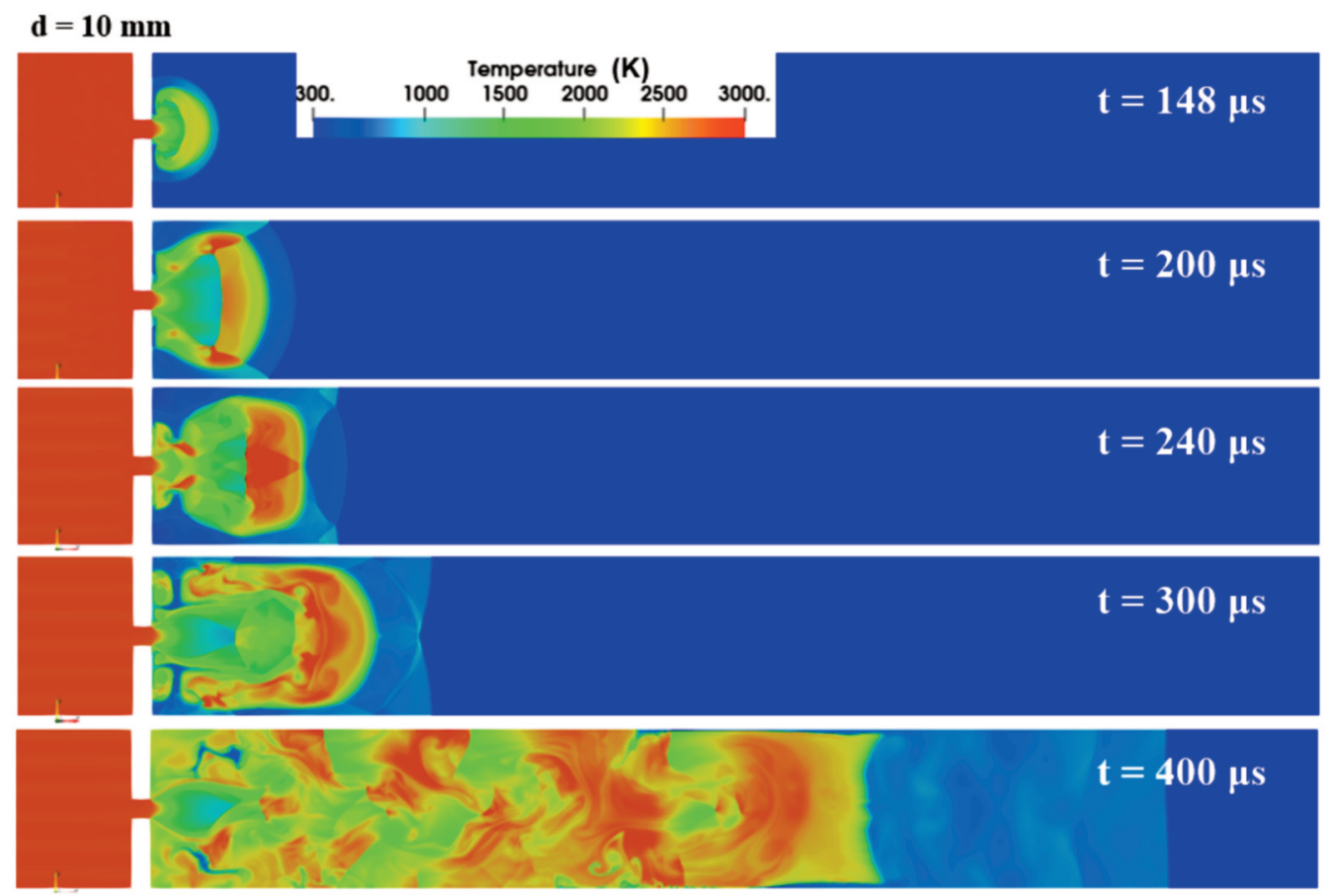

Fig. 11. Temperature contours for detonation wave propagation through a $10 \mathrm{~mm}$ orifice hole.

At time $\mathrm{t}=240 \mu \mathrm{s}$ the reflected shock ignites some of the unreacted zone with high pressure but is not able to completely burn the whole unreacted zone behind the shockwave. The shockwave travels at higher speed and the unreacted triple point merges as the shock progresses in the confined area of the tube at $\mathrm{t}=300 \mu \mathrm{s}$. The size of the unreacted zone between shock and flame increases. Although the unreacted zone is compressed, it is not compressed enough to ignite the unreacted zone. At time $\mathrm{t}=400 \mu \mathrm{s}$ the gap between flame front and shock front increases up to $120 \mathrm{~mm}$ and almost doubles at $\mathrm{t}=800 \mu \mathrm{s}$. The failure of the reflected shock to completely burn the compressed premixed mixture behind the shock front leads to failure in re-initiation of the detonation front.

The current study develops an understanding of the re-initiation phenomenon for detonation wave propagation in a premixed argon diluted hydrogen-oxygen mixture at $10 \mathrm{kPa}$ in a single obstacle laden tube. Although the study is based only on two-dimensional simulations, it does confirm the critical diameter for detonation propagation through an obstacle. A three-dimensional study may be required 
in the future for details of flow structure formation in re-initiated detonation wave analysis. Also, the simulation needs to be validated for further accurate modelling of detonation propagation. The limiting value of re-initiation will also be highly dependent on the three-dimensional structure of detonation cell-width as well as the location of the orifice hole with respect to detonation cell-width. Further validated studies may also assist in understanding the three-dimensional effect on detonation propagation through orifice holes.

\section{CONCLUSIONS}

The current study simulates detonation wave propagation through small orifice holes in a tube filled with an argon diluted hydrogen-oxygen mixture in two-dimensions by using the open-source solver AMROC. The regular detonation wave propagating in the tube was successfully modelled at $10 \mathrm{kPa}$ and $298 \mathrm{~K}$ for a $\mathrm{H}_{2}: \mathrm{O}_{2}$ :Ar composition of 2:1:7. The detonation front travels at CJ speed $1638.5 \mathrm{~m} / \mathrm{s}$ before it reaches the orifice. The propagation of the detonation front was simulated through different orifice holes ranging from $6 \mathrm{~mm}$ to $50 \mathrm{~mm}$ diameter, which corresponds to $0.375 \lambda$ to $3.125 \lambda$, where $\lambda$ is the detonation cell width in the operating case. For all the cases studied, it was found that the detonation wave decouples into slow flame and fast shockwave after passing through the orifice holes. Whether the decoupled shock and flame further re-initiate and develop the detonation front or fail to re-initiate and propagate separately depends on the orifice hole diameter.

It was observed that in the cases involving an orifice hole with a diameter less than the detonation cell-width, there is failure in detonation propagation through it. The fast shock wave travels ahead of the travelling deflagration flame and the shock unreacted region grows between shock front and flame front. The flow features and mechanisms of re-initiation were discussed herein for the limiting case of $\mathrm{d}=\lambda$, the $16 \mathrm{~mm}$ diameter orifice hole. Multiple re-initiation attempts are observed, which finally lead to re-initiation some distance from the orifice location. In cases where the orifice diameter is greater than the detonation cell-width, $d>\lambda$, it was observed that the shock and flame re-couple and form a detonation front because of shock reflections from the tube walls. The duration and distance of re-initiation reduces significantly as the orifice hole diameter increases.

Overall, this study successfully modelled the detonation wave propagation through small orifice holes and develops a further understanding of detonation propagation through re-initiation or failure in propagation. In future work, further validation of the modelling with experimental data will be conducted and a three-dimensional study on modelling the viscous effects for a wide range of operating parameters will be carried out. Also, it will be interesting to utilize the developed modelling method to validate the experimental data not only for hydrogen fuel, but also for various other fuels and fuel-blends with detailed chemical kinetics.

\section{Acknowledgment}

The authors would like to acknowledge and thank the Enterprise Research and Incubation Centre (ERIC) at Institute of Technology Carlow, Ireland for providing access to the computing resources for this study.

\section{REFERENCES}

[1] IEA, 2019, The Role of Gas in Today's Energy Transitions, IEA Publications Paris, https://www.iea.org/reports/the-role-of-gas-in-todays-energy-transitions (Accessed on 20/11/2020).

[2] Europian Commission, 2020, A hydrogen strategy for a climate-neutral Europe, Communication COM/2020/301, https://ec.europa.eu/energy/sites/ener/files/hydrogen_strategy.pdf (Accessed on 20/11/2020). 
[3] IEA, 2020, Current limits on hydrogen blending in natural gas networks and gas demand per capita in selected locations, IEA, Paris https:/www.iea.org/data-and-statistics/charts/current-limits-onhydrogen-blending-in-natural-gas-networks-and-gas-demand-per-capita-in-selected-locations (Accessed on 20/11/2020).

[4] Wolański, P., 2013, "Detonative propulsion," Proceedings of the Combustion Institute, 34(1), pp. 125-158, doi: 10.1016/j.proci.2012.10.005.

[5] Lee, J. H. S., 2008, The Detonation Phenomenon, Cambridge University Press, NY, USA. doi: 10.1017/CBO9780511754708.

[6] Oran, E. S., and Gamezo, V. N., 2007, "Origins of the deflagration-to-detonation transition in gasphase combustion," Combustion and Flame, 148(1-2), pp. 4-47, doi: 10.1016/j.combustflame.2006.07.010.

[7] Wu, Y., Zheng, Q., and Weng, Ch. 2018, "An experimental study on the detonation transmission behaviours in acetylene-oxygen-argon mixtures,” Energy, 143, pp. 554-561, doi: 10.1016/j.energy.2017.11.019.

[8] Wang, L.-Q., Ma, H.-H., Shen, Zh.-W., and Chen, D.-G. 2018, "Experimental study of DDT in hydrogen-methane-air mixtures in a tube filled with square orifice plates," Process Safety and Environmental Protection, 116, pp. 228-234, doi: 10.1016/j.psep.2018.01.017.

[9] Li, Q., Fan, W., Yan, Ch., and Ye, B., 2007, "Experiment on Kerosene-Fueled PDRE: DDT Enhancement by Shchelkin Spirals and Exhaust Plume," AIAA 2007-5008. 43rd AIAA/ASME/SAE/ASEE Joint Propulsion Conference \& Exhibit, doi: 10.2514/6.2007-5008.

[10] Ciccarelli G., and Boccio J. L., 1998, "Detonation wave propagation through a single orifice plate in a circular tube", International Symposium on Combustion, 27(2), pp. 2233-2239, doi: 10.1016/S0082-0784(98)80072-6.

[11] Knystautas R., Lee J. H., and Guirao C. M., 1982, "The critical tube diameter for detonation failure in hydrocarbon-air mixtures," Combustion \& Flames, 48, pp. 63-83, doi: 10.1016/00102180(82)90116-X.

[12] Peraldi O., Knystautas R., amd Lee J. H., 1988, "Criteria for transition to detonation in tubes," Symposium (International) on Combustion, 21(1), pp. 1629-1637, doi: 10.1016/S00820784(88)80396-5.

[13] Zhang B., amd Liu H., 2017, "The effects of large scale perturbation-generating obstacles on the propagation of detonation filled with methane-oxygen mixture," Combustion \& Flame, 182, pp. 279-287, doi: 10.1016/j.combustflame.2017.04.025.

[14] Sun X., Li Q., and Shouxiang Lu, 2019, "The propagation mechanism of detonation wave in a round tube filled with larger blockage ratio orifice plates", International Journal of Hydrogen Energy, 11, pp. 7681-7691, doi: 10.1016/j.ijhydene.2019.01.139.

[15] Deiterding R., 2003, "Parallel adaptive simulation of multi-dimensional detonation structures;" PhD thesis, Brandenburgische Technische Universität Cottbus. (Accesed on 28/11/2020) http://rdeiterding.website/pub/thesis_us.pdf

[16] Deiterding R., 2009, "A parallel adaptive method for simulating shock-induced combustion with detailed chemical kinetics in complex domains," Computers \& Structures, 87(11-12), June 2009, pp. 769-783, doi:10.1016/j.compstruc.2008.11.007.

[17] Liang, Z., Browne, S., Deiterding, R., and Shepherd, J., 2007, "Detonation front structure and the competition for radicals," Proceedings of the Combustion Institute, 31(2), pp. 2445-2453. doi: 10.1016/j.proci.2006.07.244.

[18] Mahmoudi Y., Karimi N., Deiterding R., and Emami S., 2014, "Hydrodynamic Instabilities in Gaseous Detonations: Comparison of Euler, Navier-Stokes, and Large-Eddy Simulation,” Journal of Propulsion and Power, 30(2), pp. 384-396, doi: 10.2514/1.B34986. 
[19] Deiterding R., and Bader G., 2005, "High-resolution simulation of detonations with detailed chemistry," In: Warnecke G. (editor) Analysis and Numerics for Conservation Laws, pp. 69-91, Springer, Berlin, Heidelberg, doi: 10.1007/3-540-27907-5_4.

[20] Deiterding, R., 2011, "High-resolution numerical simulation and analysis of Mach reflection structures in detonation waves in low-pressure $\mathrm{H} 2-\mathrm{O} 2-\mathrm{Ar}$ mixtures: a summary of results obtained with the adaptive mesh refinement framework AMROC," Journal of Combustion, 2011, Article ID 738969 , doi: 10.1155/2011/738969.

[21] Deiterding, R., Domingues, M. O., and Schneider, K., 2020, "Multiresolution analysis as a criterion for effective dynamic mesh adaptation - A case study for Euler equations in the SAMR framework AMROC," Computers \& Fluids, 205, 104583, doi: 10.1016/j.compfluid.2020.104583.

[22] Oran, E. S., Weber, J. W., Stefaniw, E. I., Lefebvre, M. H., and Anderson, J. D., 1998, "A Numerical Study of a Two-Dimensional H2-O2-Ar Detonation Using a Detailed Chemical Reaction Model," Combustion and Flame, 113(1-2), pp. 147-163, doi: 10.1016/S00102180(97)00218-6.

[23] Westbrook CK., 1982, "Chemical kinetics of hydrocarbon oxidation in gaseous detonations," Combustion \& Flame, 46, pp. 191-210, doi: 10.1016/0010-2180(82)90015-3.

[24] Strehlow R.A., 1968, "Gas pase detonations: Recent developments," Combustion and Flame, 12(2), pp. 81-101, doi:10.1016/0010-2180(68)90083-7.

\title{
BADANIA NUMERYCZNE PROPAGACJI FALI DETONACYJNEJ PRZEZ MALE OTWORY
}

\begin{abstract}
Abstrakt
Dążąc do lepszego zrozumienia zjawisk fizycznych leżących u podstaw propagacji fali detonacyjnej przez małe otwory (w szczególności zjawiska ponownego zapłonu lub jego brak) zbadano propagację fali detonacyjnej wzdłuż rury wypełnionej mieszaniną wodoru i tlenu rozcieńczoną argonem, w obecności przeszkody o małym otworze. Symulacje numeryczne przeprowadzono w dziedzinie dwuwymiarowej, stosując adaptacyjne dostrajanie siatki i rozwiązując równania Eulera dla wielu termicznie doskonałych próbek z reaktywnym źródłem. Mieszaninę $\mathrm{H}_{2}: \mathrm{O}_{2}$ :Ar w stosunku 2:1:7 przy ciśnieniu $10.0 \mathrm{kPa}$ i temperaturze $298 \mathrm{~K}$ zastosowano w rurze o średnicy $90 \mathrm{~mm}$ z falą detonacyjną rozchodzącą się z jednego końca. Stwierdziliśmy, że pojedynczy otwór umieszczony w odległości $200 \mathrm{~mm}$ od jednego z końców rury, o różnych średnicach $6,10,14,16,18,30$ i $50 \mathrm{~mm}$, spowodował początkowe rozdzielenie fali detonacyjnej na falę uderzeniową i czoło płomienia. Fala detonacyjna nie rozprzestrzenia się wzdłuż rury dla średnic otworu mniejszych niż $\lambda$, podczas gdy rozprzestrzenia się różnymi drogami ponownego zapłonu dla średnic otworu większych niż $\lambda$, gdzie $\lambda$ jest szerokością komórki dla regularnej propagacji detonacji.
\end{abstract}

Słowa kluczowe: detonacja, propagacja, mieszanka wodór-tlen, symulacje numeryczne, adaptacyjna siatka numeryczna 